\title{
Hızlı Üst Çene Genişletmesi Tedavisinde Palatal Rugaların Transversal Yöndeki Değişimlerinin İncelenmesi
}

\section{Examination Of Transversal Changes Of Palatal Ruga In The Treatment Of Rapid Maxillary Expansion}

\author{
Mücahid YILDIRIM*1 ${ }^{* 1}$ \\ mucahidden@gmail.com
}

\author{
Veli ŞAHİN ${ }^{1}$ \\ veli07sahin@gmail.com
}

\author{
Aybüke Emire ERDUR ${ }^{1}$ (D)
}

dtaybuke@gmail.com

\section{ÖZ}

Amaç: Adli tıp kayıtlarında, erişkinlerde hayat boyu stabil kabul edilen palatal rugaların hızlı üst çene genişletmesi (HÜÇG) tedavisi sonrasındaki transversal stabilitesinin dental model üzerinde değerlendirilmesidir.

Gereç ve Yöntemler: Çalışmamız, kliniğimizde üst çene transversal darlığı teşhis edilen, HÜÇG tedavisi uygulanan 20 hastanın (8 kız,12 erkek yaş 14.2 +-1.7 yıl) genişletme öncesi ve retansiyon sonrası kayıtlarından oluşmaktadır. Palatal rugalar 1. rugadan 3. rugaya kadar dental modeller üzerinde kurşun kalemle işaretlendi. İnter-medial (IM) ve inter-lateral (IL) ruga mesafeleri ve rugaların transversal pozisyon değişiklikleri dijital kumpas ile ölçülerek kaydedildi.

Bulgular: Yapılan ölçümler neticesinde, genişletme tedavisi sonrası rugaların IL ve IM transversal mesafe ölçümlerinde istatistiksel olarak anlamlı artış bulunmuştur ( $\mathrm{p}<.001)$. En fazla transversal artış 3. ruganın IL mesafesinde meydana gelirken; en az artış, 1. ruganın IM mesafesinde meydana gelmiştir.

Sonuç: Bu çalıșmada HÜÇG ile tedavi edilen bireylerde rugaların yerlerinin değiștiği ve kimlik belirlenmesinde stabil olmadığı bulunmuştur. Buna göre palatal ruga incelemesi ile kimlik tespiti yapılan hastaların ortodontik tedavi geçmişlerinin sorgulanması gerekmektedir.

Anahtar Kelimeler: Ortodonti, Adli tıp, Palatal ruga, Hızlı üst çene genişletmesi

\begin{abstract}
Aim: Evaluation of the transversal stability of palatal rugaes after rapid maxillary expansion (RME) treatment on a dental model, which remain stable throughout the life of the adult in the records of forensic medicine.

Materials and Methods: Our study consists of the pre-expansion and post-retention records of 20 patients (8 girls, 12 boys, $14.2+-1.7$ years) diagnosed with maxillary transversal deficiency and treated with RME in our clinic. Palatal rugae were marked simultaneously with pencil on dental models from the 1st to the 3rd ruga. Inter-medial (IM) and inter-lateral (IL) ruga distances and transversal position changes of rugae were measured with digital caliper and recorded.

Results: As a result of the measurements , a statistically significant increase was found between the IM and IL points of the 1st, 2 nd and $3 r d$ ruga after expansion ( $\mathrm{p}<.001)$. The highest increase occurred in IL distance of 3rd ruga; the least increase occurred in IM distance of 1st rugae.

Conclusion: In this study, it was found that rugaes were not stable in determining the identity in individuals treated with RME. Accordingly, the orthodontic treatment histories of the patients who are identified with palatal ruga examination should be questioned.
\end{abstract}

Keywords: Orthodontics, Forensic medicine, Palatal rugae, Rapid maxillary expansion

$\begin{array}{lll}\text { Received: } 23.11 .2020 & \text { Accepted: } 15.12 .2020 & \text { Published: } 31.12 .2020\end{array}$

Atıf / Citation: Yıldırım M, Şahin V, Erdur AE. Hızlı üst çene geniş̧letmesi tedavisinde palatal rugaların transversal yöndeki değişimlerinin incelenmesi. NEU Dent J. 2020;3:94-7.

* Sorumlu Yazar / Corresponding Author

1. Necmettin Erbakan Üniversitesi Diş Hekimliği Fakültesi Ortodonti AD Konya, Türkiye 


\section{Gíriş}

Palatal rugalar anatomik kıvrımlar veya kırışıklardır; düzensiz fibröz bağ dokusu, damağın anterior üçte birinde insiziv papillanın hemen arkasında bulunur. Ruga şekilleri; genetik, ortodonti, protez ve adli bilimler alanlarında çeșitli amaçlarla incelenmektedir. Ruga örüntüsü ve yönelimi doğum öncesi yașamın yaklaşık 12 - 14. haftasında oluşur ve ölümden sonra oral mukoza dejenere olana kadar stabil kalır. $\mathrm{Bu}$ sebeple adli tıp alanında temel yöntemler ile tespit yapılamadığı zaman palatal rugalar kimlik teșhisi amacıyla kullanılabilmektedir. ${ }^{1}$ Parmak izi gibi özgün ve karakteristik bir şekli vardır. ${ }^{2}$ Diğer yandan, palatal ruga şeklinin diş etkilerle (ortodontik tedavi, diș çekimleri, periodontal cerrahi vb.) değișebildiği ifade edilmiştir. Palatal ruga kişiye özgüdür ancak her olayda kullanılamaz. Yumuşak dokuların mevcut olduğu durumlarda ve önceki dental modellerin mevcut olduğu durumlarda alternatif kaynak olarak kullanılabilir. ${ }^{3}$ Adli odontoloji veya adli diș hekimliği, Keiser ve Neilsen ${ }^{4}$ tarafından adaletin yararına diș kanıtlarının uygun şekilde incelenmesiyle ilgilenen adli tıp dalı olarak tanımlanmıștır. Bu nedenle, mahkemeye ibraz edilen dental model stabiltesi ve tekrarlanabilirliği açısından her yönüyle kapsamlı bir şekilde araştırılmalıdır. ${ }^{4}$

Palatal rugoskopi alanında öncü, Trobo Hermosa (1932) adlı İspanyol araștırmacıdır. ${ }^{5}$ Van der Linden'in ${ }^{6}$ belgelediği üzere, anterior ruga uzunluğu 10 yaşından sonra sabit kalsa da, damak büyümesi üzerine yapılan diğer uzun dönem çalışmalar, ruga uzunluğunun yaşla birlikte değiştiğini ortaya koymuștur. $^{7-9}$ Sonrasında, bazı ortodontik yöntemlerde birinci premolar diş çekimi gibi etkiler, palatal ruga uzunluğunda veya palatal ruga genişliğinde değișikliklere neden olmuştur.,10 Ortodontik tedavi, protezler, travma, parmak emme alışkanlığı ve baskı bile rugada değișikliklere neden olabilir. ${ }^{11}$ Palatal ruganın stabilitesinin, HÜÇG tedavisinden sonra da değerlendirilmesi gerekmektedir. Bu, adli uygulamalarda kılavuz olarak palatal ruganın tanımlanmasına yardımcı olacaktır.

HÜÇG tedavisi sırasında, mid-palatal sütur transversal yönde $V$ şeklinde açılarak genişlemektedir. ${ }^{12,13}$ Çocuklarda posterior çapraz kapanış varlığı ile görülen iskeletsel üst çene darlık vakaları, diş ve doku destekli apareyler ile tedavi edilebilmektedir. ${ }^{14} \mathrm{Bu}$ çalışma, maksiller darlığı olan hastalarda midpalatal genişletme için ortodontik kuvvetlerin uygulanmasindan sonra palatal rugalarda herhangi bir değişiklik olup olmadığını değerlendirmek ve palatal rugaların bu tedavinin yapıldığı hastalarda adli kimlik tespitinde kullanılıp kullanılamayacağını araștırmak için tasarlanmıştır. Çalışmamızın sıfır hipotezi, HÜÇG ile tedavi edilen hastaların palatal rugalarında herhangi bir değişim meydana gelmemektedir.

\section{GEREÇ VE YÖNTEMLER}

$\mathrm{Bu}$ çalışma, posterior çapraz kapanıșı olan, Necmettin Erbakan Üniversitesi Ortodonti Bölümü'nde tedavi olmuş 20 adolesan hastadan $(8 \mathrm{~K}, 12 \mathrm{E}$, yaş $14.2 \pm 1.7$ yıl) alınmıs modellerin incelenmesi ile yapılan retrospektif bir çalışmadır. Çalışma için dahil edilme kriterleri; posterior çapraz kapanışı olan, dil itimi veya parmak emme gibi alışkanlıkları olmayan daha önce ortodontik tedavi görmemiş olan, radyografik muayenesinde palatinal bölgede herhangi bir patolojisi olmayan adolesan hastalardır.

Çalışmamızda kullandığımız bireylerin tedavisinde kliniğimizde rutin kullanılmakta olan HÜÇG tedavisi uygulanmıștır. Buna göre; tedavi başlangıcında model ölçüleri aljinat ile alınmıș (T1) , çalıșma modelleri için tip II alçı kullanılmıştır. Laboratuvar işlemleri ile akrilik bonded ekspansiyon apareyi aynı teknisyen tarafından imal edilmiştir. Apareyin yapıştırılmasında cam iyonomer siman kullanılmıştır. Aparey ilk hafta günde 2 çeyrek tur sonrasında günde 1 çeyrek tur çevrilmiștir. Oluşması muhtemel nüksü telafi etmek amacıyla 2-3 mm fazladan genişletme yapıldıktan sonra pasif retansiyon fazına geçilmiştir. 3-4 aylık retansiyon periyodu sonrasinda hastanın ara kayıtları alınmıştır (T2).

Kapali ve ark. ${ }^{5}$ tarafından verilen sinıflandırmaya göre yeterli ışık altında $0.3 \mathrm{~mm}$ kurşun kalemle eşzamanlı olarak genişletme öncesi ve retansiyon sonrası modeller üzerinde işlemler yapıldı. Medial (M) ve lateral (L) noktalar, birinci, ikinci ve üçüncü ruganın medial ve lateral uçlarında işaretlendi. İnter-medial (IM) ve inter-lateral (IL) ruga mesafesi $0,1 \mathrm{~mm}$ hassasiyetle dijital kumpaslar yardımıyla ölçüldü. ${ }^{17}(\mathrm{Re}-$ $\operatorname{sim} 1$ ). Buna göre birinci rugaların medial noktaları arası mesafe, tedavi öncesinde (A) IMA1, tedavi sonrasında (B) IMB1 ile gösterilmiștir. Birinci rugaların lateral noktaları arasındaki uzunluk değerleri tedavi öncesinde ILA1, tedavi sonrasinda ILB1 ile gösterilmiştir. Aynı ölçümler 2. ve 3. rugalar için de tekrar edilmiş ve aynı şekilde kısaltılmıştır.

Resim 1: Modeller üzerinde ölçülen noktaların kurșun kalem ile çizilerek gösterilmesi

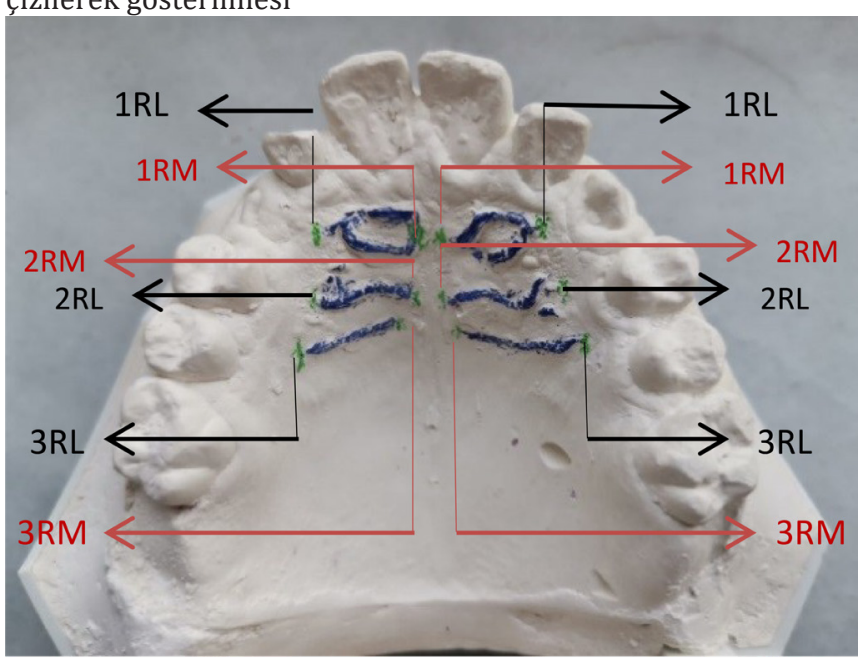

1R: Birinci Ruga; 2R: İkinci Ruga; 3R: Üçüncü Ruga; M: Medial; L: Lateral 


\section{İstatistiksel Analiz}

Metot hatasının tespiti amacıyla, ölçümler aynı hekim tarafından aynı şartlar altında bir hafta sonra tekrarlanmıștır. Ölçümler arası farklılıklar pearson korelasyon analizi ile incelendiğinde iki farklı zamanda yapılan ölçümler arasında çok yüksek korelasyon tespit edilmiștir. ( $\mathrm{r}=0.94)$ Rugalar için IM ve IL mesafelerin tedavi öncesi ve sonrası karşılaștırılmasında değerlerin normalitesi shapiro-wilk normalite testi ile incelenmiştir. Veriler normal dağılım gösterdiği için bağımlı örneklem t-test istatistiksel analiz yöntemi kullanılmıștır. (SPSS 21.0; SPSS Inc., Chicago, IL, USA)

\section{BULGULAR}

HÜÇG aktif tedavi süresi ortalama $26.13 \pm 5.36$ gün olarak kaydedilmiştir. Aktif tedavi periodu ile $2 \mathrm{~mm}$ fazladan düzeltim yapılmıştır. 3 aylık retansiyon periyodu sonucunda elde edilen sonuçlar tablo 1'de verilmiștir. Buna göre, tüm genișletme öncesi (A) ve sonrası (B) inter-medial (IM) ve inter-lateral (IL) mesafe değerlerinde istatistiksel olarak anlamlı bir artış olduğunu tespit edilmiştir. Bununla birlikte, yatay değişiklikler en fazla üçüncü ruganın inter-lateral mesafesi için, ardından birinci ruganın inter-lateral mesafesi için kaydedilmiștir.

Tablo 1: Tedavi öncesi ve retansiyon sonrası inter-rugal mesafelerin değerlendirilmesi

\begin{tabular}{|c|c|c|c|c|c|}
\hline \multicolumn{2}{|c|}{ T1 } & \multicolumn{2}{c|}{ T2 } & Fark + SS & P Değeri \\
\hline $\begin{array}{c}\text { Rugalar Arası } \\
\text { Mesafe }\end{array}$ & Ort + SS & $\begin{array}{c}\text { Rugalar Arası } \\
\text { Mesafe }\end{array}$ & Ort + SS & 0.890 & $<.001^{*}$ \\
\hline IMA1 & $2.805 \pm 1.111$ & IMB1 & $3.695 \pm 0.885$ & 1.015 & $<.001^{*}$ \\
\hline IMA2 & $4.020 \pm 0.902$ & IMB2 & $5.035 \pm 1.165$ & 1.290 & $<.001^{*}$ \\
\hline IMA3 & $5.905 \pm 1.181$ & IMB3 & $7.195 \pm 1.168$ & w2.020 & $<.001^{*}$ \\
\hline ILA1 & $16.575 \pm 2.725$ & ILB1 & $18.595 \pm 2.774$ & 2.675 & $<.001^{*}$ \\
\hline ILA2 & $18.680 \pm 3.370$ & ILB2 & $21.355 \pm 2.846$ & 3.550 & $<.001^{*}$ \\
\hline ILA3 & $20.470 \pm 3.680$ & ILB3 & $24.020 \pm 3.206$ & \\
\hline
\end{tabular}

1: Birinci Ruga; 2: İkinci Ruga; 3: Üçüncü Ruga; A:Tedavi Öncesi; B: Retansiyon Periodu Sonrası; IM: Inter-Medial; IL: Inter-lateral Ort: Ortalama Değer SS: Standart Sapma; P: Anlamlılık Değeri

*: İstatistiksel olarak anlamlı değer

\section{TARTIȘMA}

Bu çalıșma, HÜÇG tedavisi yapılan adölesan hastalarda palatal ruganin birincil adli kimlik belirleme kriteri olarak rolünü tespit etmek ve yatay boyutta palatal ruganın HÜÇG tedavisindeki stabilitesini belirlemek için yapılmıştır. Konu ile ilgili benzer çalışmalar mevcut olsa da gelișen teknoloji ile birlikte hastalardan alınan dijital ölçü kayıtları sayesinde gelecekte her hastanın ölçü kayıtlarına rahatlıkla ulașılabilecektir. $\mathrm{Bu}$ durum da gelecekte bir kimlik teşhisi gerektiğinde ciddi kolaylık sağlayacaktır. Ortodontik tedavi sirasinda hastalardan rutin olarak model kayıtları alınmakta ve saklanmaktadır. Hali hazırda hastalar devlet kurumlarındaki tüm tahlil ve radyoloji kayıtlarını internet ortamında görebilmekte iken gelişen teknoloji ile birlikte bunun dijital model kayıtları için de olması şaşırtıcı karşılanmamalıdır. Gelecekte dijital kayıtlar hastaların bilgi bankalarına yüklendiğinde yapılan tedavilerin palatal bölge anatomisini değiștirip değiștirmediği de daha önemli bir konu haline gelecektir. Bu sayede palatal rugaların kimlik tespiti için kullanımının da yaygınlaşması beklenmektedir.

Sonuçlarımız, büyüme ve ortodontik tedavi ile palatal rugada uzunluk ve pozisyon değişikliklerinde daha önce yapılmıș olan çalıșmalarla da uyumludur. Literatürde konu ile ilgili çalıșmalar incelendiğinde, çekimli ortodontik tedavilerde ${ }^{2,4}$, çekimsiz ortodontik tedavilerde ${ }^{15}$, fonksiyonel tedavilerde ${ }^{16}$, HÜÇG tedavisinde ${ }^{17}$ meydana gelen palatal ruga değişimlerini değerlendiren birçok çalıșmanın yapıldığı tespit edilmiștir. Bu nedenle, palatal rugaların HÜÇG tedavisi yapılmış adölesan bireylerde ayırt edici teşhis için sabit referans noktaları olarak kabul edilip edilemeyeceklerinin hala araştırılması gerekmektedir.

Çalışmamızın sonuçları neticesinde, birinci, ikinci ve üçüncü rugaların ara mesafelerinde yatay boyutlarda bir artış olduğu kaydedildi ve en az değişiklik birinci ruganın inter-median mesafesinde izlendi. Çalıșmamız, birinci palatal ruga seviyesinde inter-rugal mesafenin daha az değișiklik gösterdiği bulgusunu da desteklemektedir. Ayrıca, lateral noktalar arası mesafeler tüm gruplarda istatistiksel olarak anlamlı değișiklikler kaydetti. Literatürde rugaların medial noktalarının daha stabil referans noktaları olduğu belirtilmiștir. ${ }^{16}$ Çalıșmamızda da en yüksek üçüncü palatal ruganın uzunluklarının arttığı kaydedilmiştir ancak değerler lateral noktalarda medial noktalara göre daha büyüktür. Normal gelișim gösteren çocuklarda ve ayrıca birinci küçük azı dişlerinin çekilmesi ile ortodontik tedavi gören hastalarda lateral ruga değişiklikleri bildirilmiștir. ${ }^{2,6}$ Çekim boşluğunda maksiller anterior dișlerin retraksiyonuna bağlı in- 
ter-lateral ruga değișiklikleri bildirilmesine rağmen, bu yayın genişletme kuvvetlerinin kullanıldığı çalıșmamızla doğrudan ilişkili değildir.

İlk ruganın medial noktalarının yatay değerler için etkilenmediği van der Linden ${ }^{6}$ ve Almeida ve ark. ${ }^{16}$ tarafından yapılan çalıșmalarda doğrulanmıștır. Bununla birlikte, çalışmamızda, yapılan tüm ölçümlerde anlamlı bir artış meydana gelmiștir. Çalışmamız sonuçlarının tamamının istatistiksel olarak anlamlı olmasının sebebi genişletme miktarının fazla olması ve kullanılan apareyin farklı olmasından kaynaklanabilir. Shukla ve ark. ${ }^{11}$ tarafından yapılan çalıșmada, çekimli ve çekimsiz ortodontik tedavi edilen hastaların modelleri tedavi öncesi ve sonrası karşılaştırılmıștır. Lateral ruga noktalarında kaydedilen değișim çalışmamız sonuçlarını desteklemektedir. Yapılan tüm bu çalışmalarla ortodontik tedavilerin rugalardaki stabilizayonu değiștirdiği tespit edilmiștir.

\section{SONUÇ VE ÖNERILLER}

Adli kimlik tespiti için stabil referans yer işaretleri olarak kullanılacak medial ve lateral rugalar arası mesafenin HÜÇG tedavisini takiben transversal olarak arttığı tespit edilmiştir. Bu değişiklik sırasıyla 3. , 2. ve 1. Rugalarda meydana gelmiştir. Dolayısıyla palatal rugaların adli tıp teşhisinde kullanımı için ortodontik tedavi geçmişinin sorgulanması gerekmektedir. Sıfır hipotezi reddedilmiștir.

$\mathrm{Bu}$ çalışmada, küçük bir örneklem büyüklüğünde HÜÇG tedavisindeki transversal değișiklikler değerlendirilmiștir. $\mathrm{Bu}$ hastalarda adli kimlik belirleme için referans yer ișaretleri olarak kabul edilmekte olan palatal ruganın tedavi sonundaki stabilitesi sorgulanmıştır. Bununla birlikte, bu çalışmanın daha büyük bir örneklem büyüklüğünde, potansiyel büyüme dönemi sonuna kadar takip edilmesi ve tedavi edilmeyen bir kontrol grubu ile de karșılaștırılması ve dijital model kayıtları ve ölçümleri ile yapılması gelecekteki çalışmalar için önerimizdir. Midpalatal genişletme yapılan hastalarda palatal ruganın stabilitesini, adli uygulamalarda dikkate alınması gereken yatay boyut değişikleri açısından araştırmış olsak da, daha sonraki çalışmalarda dikey ve ön-arka boyuttaki değişikliklerin de dikkate alınması gerekmektedir. Palatal rugaların ante-mortem verilerinin mevcudiyetine dayalı olarak adli tıpta kullanılması için olası tedavi yöntemleri sırasındaki stabilitesi araștırıldıktan sonra daha kesin sonuçlara ulaşılabileceğine inaniyoruz.

\section{KAYNAKLAR}

1. Jain A, Chowdhary R. Palatal rugae and their role in forensic odontology. J Investig Clin Dent, 2014;5:1718.

2. Patil MS, Patil SB, Acharya AB. Palatine rugae and their significance in clinical dentistry: a review of the literature. J Am Dent Assoc, 2008;139:1471- 8.

3. Ohtani M, Nishida N, Chiba T, Fukuda M, Miyamoto Y, Yoshioka N. Indication and limitations of using palatal rugae for personal identification in edentulous cases. Forensic Sci Int, 2008;176:178-82.

4. Keiser and Neilsen S. Person Identification by Means of Teeth. Bristol: John Wright and Sons; 1980.

5. Kapali S, Townsend G, Richards L, Parish T. Palatal rugae patterns in Australian aborigines and caucasians. Aust Dent J, 1997;42:129-33.

6. van der Linden FP. Changes in the position of posterior teeth in relation to ruga points. Am J Orthod, 1978;74:142-61.

7. Lysell L. Plicae palatinae transversae and papilla incisiva in man; a morphologic and genetic study. Acta Odontol Scand, 1955;13:5-137.

8. Muthusubramanian M, Limson KS, Julian R. Analysis of rugae in burn victims and cadavers to simulate rugae identification in cases of incineration and decomposition. J Forensic Odontol, 2005;23:26-9.

9. Levine S. Forensic odontology-Identification by dental means. Aust Dent J, 1977;22:481-7.

10. Peavy DC Jr, Kendrick GS. The effects of tooth movement on the palatine rugae. J Prosthet Dent, 1967;18:536-42.

11. Shukla D, Chowdhry A, Bablani D, Jain P, Thapar R. Establishing the reliability of palatal rugae pattern in individual identification (following orthodontic treatment). J Forensic Odontol, 2011;29:20-9.

12. Hass AJ. Rapid expansion of maxillary dental arch and nasal cavity by opening the mid palatal suture. Angle Orthod, 1961;31:73-90.

13. Leonardi R, Sicurezza E, Cutrera A, Barbato E. Early post-treatment changes of circumaxillary sutures in young patients treated with rapid maxillary expansion. Angle Orthod, 2011;81:36-41.

14. Weissheimer A, de Menezes LM, Mezomo M, Dias DM, de Lima EM, Rizzatto SM. Immediate effects of rapid maxillary expansion with Haas-type and hyrax-type expanders: A randomized clinical trial. Am J Orthod Dentofacial Orthop, 2011;140:366-76.

15. Caldas IM, Magalhães T, Afonso A. Establishing identity using cheiloscopy and palatoscopy. Forensic Sci Int, 2007;165:1-9.

16. Almeida MA, Phillips C, Kula K, Tulloch C. Stability of the palatal rugae as landmarks for analysis of dental casts. Angle Orthod, 1995;65:43-8.

17. Kapoor P, Miglanı R. Transverse changes in lateral and medial aspects of palatal rugae after mid palatal expansion: A pilot study. J Forensic dent sci, 2015;7(1):8. 